Vol 3, No. 1, Agustus 2020: 171 -177, DOI: $\underline{\text { https://doi.org/10.34007/iehss.v3i1.245 }}$

\title{
Upaya Meningkatkan Hasil Belajar Menggambar Bentuk Buah Teknik Krayon
}

\section{Efforts to Improve Learning Outcomes in Drawing the Fruit Shape of Crayon Technique}

\author{
Nurul Cindy Paramita Asdi Sitanggang*, Azmi \& Adek Cerah Kurnia Azis \\ Program Studi Pendidikan Seni Rupa, Jursan Seni Rupa, Fakultas Bahasa Dan Seni \\ Universitas Negeri Medan
}

Diterima: 16 Juli 2020 ; Disetujui : 02 Agustus 2020 ; Dipublish : 04 Agustus 2020

*Email: nurulcindyparamita14@gmail.com

\begin{abstract}
Abstrak
Tujuan penelitian ini adalah untuk meningkatkan kualitas gambar anak dari yang tidak mengetahui menjadi paham akan dasar gambar yaitu gambar bentuk buah dengan penerapan metode latihan (drill) dalam kegiatan mewarnai media krayon di kelas VI-A SD Negeri No. 081232 Sibolga. Metode Latihan adalah metode yang dapat digunakan untuk menyampaikan materi pelajaran atau informasi melalui bentuk latihan-latihan secara berulang-ulang agar siswa memiliki ketangkasan atau keterampilan yang lebih tinggi dari apa yang dipelajari. Adapun subjek penelitian berjumlah 29 siswa. Metode latihan ini menggunakan tindakan Pre Test, Siklus I, Siklus II, guna meningkatkan hasil belajar siswa. Secara bertahap pada tindakan pre test, peneliti mendapati rata-rata nilai presentase belajar masih $52 \%$ dilanjut dengan siklus I didapati rata-rata belajar siswa yang baik 86,7\% dan cukup baik 13,3\% dengan artian sudah mulai baik. Kemudian lebih ditingkatkan pada siklus II peneliti mendapati 89,66\% amat baik dan 10,34\% baik, dapat dikatakan bahwa perbaikan hasil belajar siswa menjadi lebih baik dan meningkat. Maka peneliti memutuskan untuk tidak melanjuti tindakan pada kegiatan mewarnai gambar bentuk buah. Penerapan metode latihan (drill) telah berhasil dilakukan dan dapat menjadi acuan dan strategi belajar seni rupa khususnya menggambar.
\end{abstract}

Kata Kunci: Metode Latihan, Menggambar Bentuk, Media Krayon

\begin{abstract}
The purpose of this study was to improve the quality of images of children from those who did not know to understand the basic image of the fruit shape drawing by applying the drill method in coloring crayon media activities in class VI-A of SD Negeri No. 081232 Sibolga. Training Method is a method that can be used to convey subject matter or information through repeated forms of exercises so that students have dexterity or skills higher than what is learned. The research subjects totaled 29 students. This training method uses the Pre Test action, Cycle I, Cycle II, to improve student learning outcomes. Gradually in the pre-test action, researchers found the average value of learning percentage is still $52 \%$ followed by the first cycle found an average student learning is good at $86.7 \%$ and quite good at $13.3 \%$ in the sense that it has started well. Then further improved in the second cycle researchers found $89.66 \%$ very good and $10.34 \%$ good, it can be said that the improvement in student learning outcomes for the better and improved. Then the researchers decided not to continue the action on the activity of coloring pictures of fruit shapes. The application of the training method (drill) has been successfully carried out and can be a reference and a strategy for learning fine arts, especially drawing.
\end{abstract}

Keyword : Crayon Media, Drawing Shapes, Training Methods

How to Cite: Sitanggang, N.C.P.A., Azmi \& Azis, A.C.K. (2020). Upaya Meningkatkan Hasil Belajar Menggambar Bentuk Buah Teknik Krayon. Journal of Education, Humaniora and Social Sciences (JEHSS). 3 (1): 171-177.

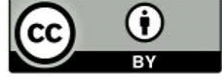




\section{PENDAHULUAN}

Tujuan Pendidikan Seni Rupa di sekolah dasar (SD) adalah melanjutkan dan mengembangkan kesanggupan berkarya maupun pengetahuan seni rupa yang telah dimiliki anak sebelum memasuki sekolah. Ketika masuk sekolah dasar (SD), siswa telah memiliki sedikit daya sensitivitas dan kreativitas. Hal ini perlu diperhatikan, Anak Sekolah Dasar (SD) berusia sekitar 6 - 12 tahun sebagai masa sekolah perlu didukung oleh guru agar masa peka ini dapat dimanfaatkan secara maksimal oleh para siswa. Tahap-tahap perkembangan menggambar/seni rupa secara garis besar dapat dibedakan dua tahap karateristik, yaitu kelas I sampai dengan kelas III ditandai dengan kuatnya daya-daya fantasi-imajinasi, sedangkan kelas IV sampai dengan kelas VI ditandai dengan mulai berfungsinya kekuatan rasio.

Pada umumnya semua periodisasi yang dikemukakan oleh para ahli memiliki kesamaan, misalnya dimulai dari dua tahun. Periodisasi masa perkembangan seni rupa anak menurut Viktor Lowenfeld dan Lambert Brittain dalam: Creative and Mental Growth meliputi: Masa Mencoreng (Scribbling), 2-4 tahun. (2) Masa Prabagan (Preschematic), 4-7 tahun. (3) Masa Bagan (Schematic Period), 7-9 tahun. (4) Masa Realisme Awal (Dawning Realism). 9-12 tahun. (5) Masa Naturalisme Semu (Pseudo Naturalistic). 12-14 tahun. (6) Masa Penentuan (Period of Decision), 14-17 tahun.

Adapun gagasan Catur Budi dalam (Mulyani, 2017: 60) menjelaskan: "Pendidikan Seni Rupa adalah mengembangkan keterampilan menggambar, menanamkan kesadaran budaya lokal, mengembangkan kemampuan apresiasi seni rupa, menyediakan kesempatan untuk mengaktualisasi diri, mengembangkan penguasaan disiplin ilmu seni rupa, dan mempromosikan gagasan multikultural".

Dilanjut dengan menurut Rofian (2016) menjelaskan: "Dalam konsep pembelajaran khususnya seni rupa, ada tiga aspek yang dituangkan yakni kognitif (pengetahuan), afektif (sikap/apresiatif) dan psikomotorik (soft skills). Sehingga dalam pelaksanaan pembelajaran di kelas, guru tidak hanya menyampaikan materi dengan hanya sekedar memaparkan materi secara lisan saja. Namun seorang guru juga dituntut untuk mampu memberikan contoh secara langsung praktik membuat sebuah karya di kelas".

Diketahui bahwa kualitas menggambar siswa SD ini rata-rata masih belum memasuki bentuk-bentuk dasar gambar bentuk yang tepat. Karna dari hasil peneliti tinjau langsung mereka mendapati nilai yang cukup tinggi setiap kali menggambar oleh sang Guru tetapi jika dinilai sendiri oleh peneliti bahwa angka nilai 90 ke atas ini, masih belum layak memasuki/mendapati kategori penilaian hasil gambar yang dimana jika dibandingkan dengan apsek-aspek kaidah pendukung dasar gambar bentuk itu sendiri. Bila dikaji ulang bahwa, menjadi indikator penilaian kelayakan sebuah karya gambar bentuk buah yang baik, yaitu: 1) komposisi, 2) proporsi, 3) ketepatan bentuk, dan 4) kesesuaian warna/gradasi.

Sebab menurut Tabrani (2012), yang di gambar anak, bukan semata apa yang dilihatnya, tapi merupakan hasil kerajsama semua indera-indera, yang ia rasakan dan imajinasi serta dicetuskan jadi sebuah gambar. Karna bagi anak, yang penting prosesnya, kegiatan menggambar bukan hasilnya.

Berdasarkan observasi di awal yang dilakukan oleh peneliti. Wawancara awal, 30 Juli 2019 dengan guru Seni Budaya di SD Negeri No. 081232 Sibolga; Hendra Gunawan Pulungan, S.Pd. SD yang mengatakan: Hasil belajar siswa dalam membuat karya gambar bentuk jika dilihat dari proses pembelajaran keadaan siswa dianggap kurang berminat tetapi masih ada beberapa dari siswa yang bersemangat dalam berkarya, mulai teknik dasar menggambar, pencapaian proposi, hingga paling menyulitkan bagi siswa dalam perpaduan warna menggunakan krayon atau istilah lain Gradasi.

\section{METODE PENELITIAN}

Adapun metode yang digunakan dalam penelitian ini adalah metode deskriptif dan teknik analisis kualitatif. Metode yang digunakan dalam penelitian ini adalah metode kualitatif, dan teknik pengumpulan data yang digunakan adalah Participant Observation (observasi berperan serta) dan dokumentasi yang dikaitkan dengan peranan Metode Latihan pada tahap tingkatan 
Vol 3, No. 1, Agustus 2020: 171 -177, DOI: https://doi.org/10.34007/iehss.v3i1.245

lapangan, guna menjalankan keberhasilan suatu tindakan penelitian. Serta merta Penelitian dengan pendekatan kualitatif bersifat deskriptif, dengan mengumpulkan data lunak (soft data), yang berupa penelitian lapangan (field research).

Penelitian ini bersifat melakukan perbaikan pembelajaran kerena penelitian ini merupakan Penelitian Tindakan Kelas (Classroom Action Research), yakni studi sistematis yang dilakukan dalam upaya perbaikan praktik-praktik pendidikan dengan melakukan tindakan praktis serta refleksi dari tindakan tersebut. Menurut Dewi (2015), Penilaian Tindakan Kelas ialah upaya yang dilakukan secara terencana dan sistematis dengan melakukan refleksi terhadap praktik selanjutnya tindakan perbaikan atau peningkatan pembelajaran/pendidikan.

Disini peneliti menggunakan terapan metode drill guna merangsang dan memfokuskan pikiran siswa untuk dapat lebih optimal menangkap dan mengingat bentuk objek yang ia serap serta dapat di tuangkan pada gambar yang layak di nilai dan dapat dibandingkan dengan baik dan buruk masing-masing karya.

Adapun Urutan Pelaksanaan Metode Latihan Ini Yang Telah Diberikan Dapat Dilihar Sebagai Berikut: 1) Tahap Persiapan, Pada bagian ini dimulai dengan persiapn guru memberikan contoh materi dasar gambar bentuk lalu guru juga menyampaikan tujuan-tujuan yang hendak dicapai dari pembelajarn tersebut. Serta guru memberikan motivasi agar siswa memahami fungsional dari kegiatan belajar mengajar berlangsung; 2) Tahap Pelaksanaan, Langkah-lamgkah pelaksanaan metode latihan keterampilan dalam pembelajaran gambar bentuh buah yaitu: a) Langkah Pertama, sebelum latihan dilaksanakan siswa lebih dahulu diberi penjelesan materi mengenai arti atau manfaat dan tujuan dari latihan gambar bentuk buah tersebut; b) Langkah Kedua, kegiatan dilakukan secara bertahap guna merangsang kognitif dan psikomotorik berjalan dengan seimbang. Selama latihan berlangsung, guru hendak memperhatikan bagian-bagian mana yang sebagian besar anak-anak dirasakan sulit. Supaya siswa yang merasakan kesulitan maka guru memberikan contoh garis pada karya siswa dan mengajak fokus pada garis bentuk buah dengan benda aslinya; 3) Evaluasi, Evaluasi dilakukan pada setiap akhir pertemuan, dengan cara siswa diminta untuk mengumpulkan hasil latihan yang telah dikerjakan per setiap tahap siklus yang diterapkn. Kemudian guru dengan mudah dapat mengecek pada bagian mana saja siswa lebih mengalami kesulitan dan guru dapat membahasnya kembali pada pertemuan berikutnya.

Untuk memecahkan masalah dalam penelitian ini diperlukan hopotesis sebagai alat penuntunya. Yusuf (2016), menjelaskan, "Hipotesis adalah suatu dugaan sementara, suatu tesis sementara yang harus dibuktikan kebenarannya melalui penyelidikan ilmiah. Berdasarkan perumusan masalah yang dikemukakan peneliti mengambil suatu hipotesa bahwa: Diduga dengan alat peraga langsung objek buah dapat memfokuskan dan merangsang daya ingat siswa

Dengan ini Metode Latihan akan dapat meningkatkan hasil belajar gambar bentuk siswa di kelas VI SD Negeri No. 081232 Sibolga T.A 2019/2020 dan bila ditemukan kesalahan akan dilanjutkan dengan tindakan siklus dan bantuan media mencontoh di papan tulis oleh peneliti hingga hasil gambar siswa meningkat dengan baik.

\section{HASIL DAN PEMBAHASAN Produk Awal Siswa}

Bisa kita lihat di gambar 1, 2 dan 3, ialah penampakan dari salah satu karya-karya yang sudah pernah di kerjakan oleh siswa kelas VI SD Negeri No. 081232 Sibolga yang bertemakan Pemandangan didapati Guru memberikan nilai cukup tinggi $(<90)$ pada setiap gambar yang mana bila dikoreksi lebih teliti lagi bisa didapti suatu karya yang tidak cocok untuk mendapati angka 9 sehinggan tak ada bandingan nilai baik dan buruk dari setiap karya dari segi penampatan sudut gambar yang tak sesuai, ini bermaksud daripada sebagaian bandingan karya dengan keterkaitan Judul peneliti : 
Nurul Cindy Paramita Asdi Sitanggang, Azmi \& Adek Cerah Kurnia Azis, Upaya Meningkatkan Hasil Belajar

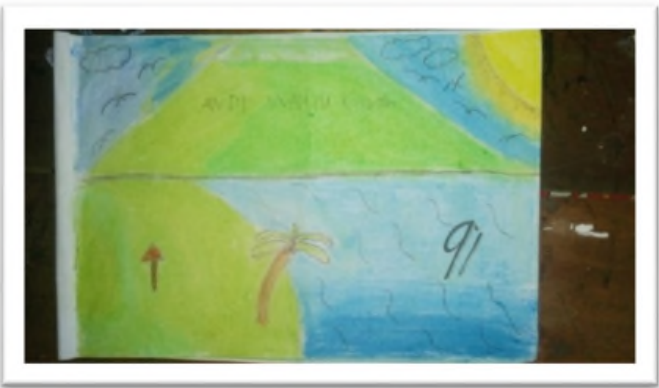

Gambar 1. Dapat dinilai keseimbangan komposisi pada setiap sudut gambar yang tidak harmonis Sumber Gambar: Nurul Cindy

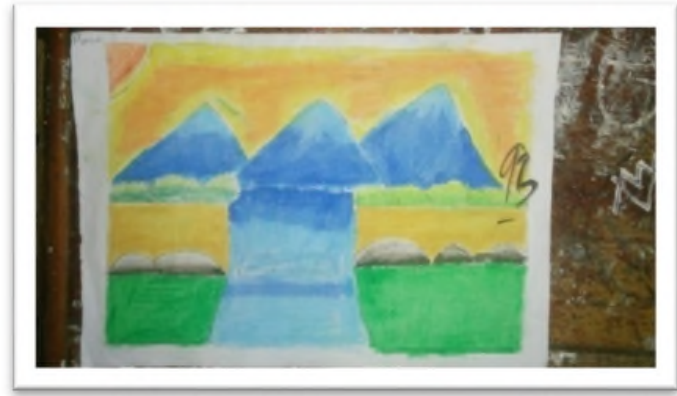

Gambar 2. Dapat dinilai keseimbangan persepektif yang kurang tajam Sumber Gambar: Nurul Cindy

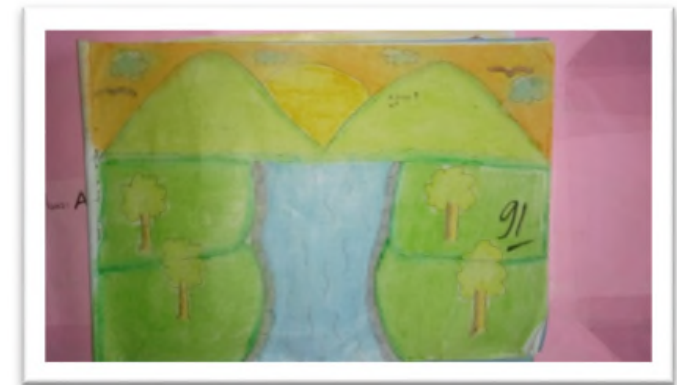

Gambar 3. Dapat dinilai kesamaan kejadian pada karya No. 2 Sumber Gambar: Nurul Cindy

\section{Hasil Setelah Latihan Drill}

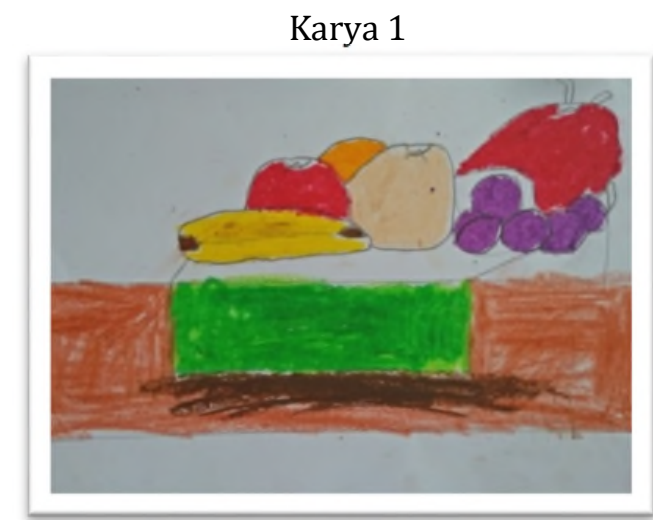

Gambar 4. Riski Aulia Rasyid

Sumber: Nurul Cindy, 2020

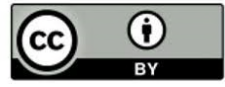

This work is licensed under a Creative Commons Attribution 4.0 
Vol 3, No. 1, Agustus 2020: 171 -177, DOI: https://doi.org/10.34007/iehss.v3i1.245

Berdasarkan hasil penelitian, ditemukan salah satu karya yang mana didapati ketentuan dari semua elemen dasar gambar bentuk karya ini tidak memenuhi semua dari elemen tersebut. Dapat dilihat bahwa siswa yang menggambar betul tidak paham atau mengetahui gambar yang baik seperti apa dan siswa tersebut tidak dapat kuat mengingat daya serap apa yang telah dilihatnya. Bisa dinilai dari komposisi saja ia tidak mampu untuk mengambil atau menyesuaikan posisi box buah pada bidang tengah kertas gambar. Ditambah lagi proporsi buah yang amburadul atau tidak beraturan hingga tak menciptkan terbentuk sebuah objek buah. Lalu pada pewarna yang berantakan dan asal-asalan. Sehingga bisa dikatakan siswa tersebut tidak bisa menggambar dan tidak paham bagaiamana harus menggambar. Dari sini saya sebagai penelitipun tersentuh untuk melakukan tindakan cepat agar dapat mengubah karya yang tidak layak ini menjadi menjadi karya yang dapat dipandang dengan baik.

Berdasarkan data-data yang telah dideskripsikan, dianalisiskan maka diperoleh bahwa karya gambar bentuk buah teknik krayon pada karya 22 dalam penerapan ketepatan komposisi, proporsi, kemiripian bentuk dan gradasi Kurang Baik dengan jumlah nilai 60, sangat jauh dari kata KKM sekolah yaitu 75.

\section{Karya 2}

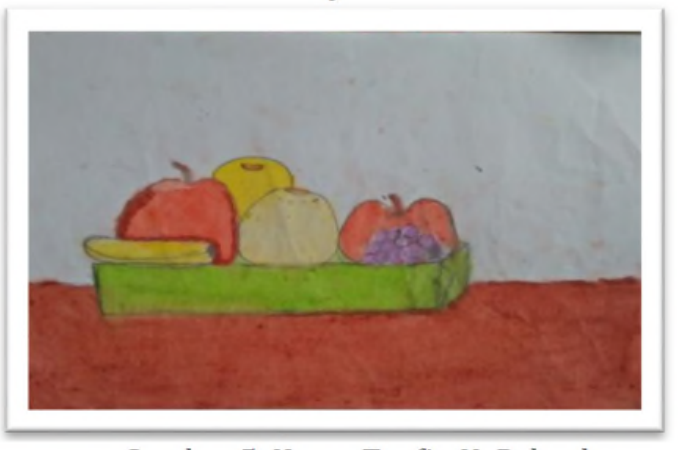

Gambar 5. Karya Taufiq H. Pakpahan

Sumber: Nurul Cindy, 2020

Kejadian serupa dengan di awal. Berdasarkan hasil penelitian, ditemukan salah satu karya yang mana didapati ketentuan dari semua elemen dasar gambar bentuk karya ini tidak memenuhi separuh dari elemen tersebut. Dapat dilihat bahawa komposisi yang terlihat lebih ke kiri, lalu disambut dengan proporsi masing-masing buah yang belum sempurna dan ditambah lagi bentuk atasan buah apel menyerupai lekukan Love lalu buah anggur yang terlalu kecil tidak dapat menyimbang dengan komposisi buah lainnya. Pada pewarnaa masih belum selesai dan pucat hingga gradasi pun tepat dipadukan.

Berdasarkan data-data yang telah dideskripsikan, dianalisiskan maka diperoleh bahwa karya gambar bentuk buah teknik krayon pada karya 26 dalam penerapan ketepatan komposisi, proporsi, kemiripian bentuk dan gradasi Cukup Baik dengan jumlah nilai 70 .

Karya 3

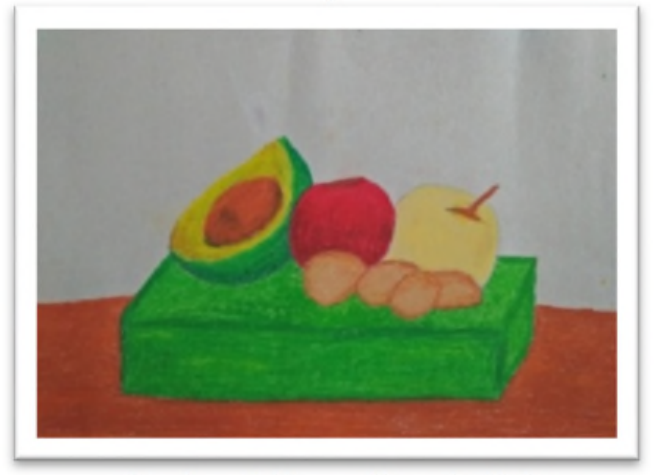

Gambar 5. Karya Alvando H. S

Sumber: Nurul Cindy, 2020

$\underset{w w}{W}$ http://mahesainstitute.web.id/ojs2/index.php/jehss

Mmahesainstitut@gmail.com 
Berdasarkan hasil penelitian, pada tindakan tahap siklus I ini bisa dilihat dari perubahan objek buah dan perubahan pada hasil karya. Salah satu karyanya, Bisa dinilai dari elemen dasar gambar bentuk yaitu komposisi yang sudah baik pada peletakan bidang tengah kertas gambar. Disambung dengan proporsi buah yang sudah tepat dan baik (layak dilihat) tapi masih ditemukan sedikit kesalahan sketas kaki buah pir, paduan warna yang menjadikan gradasi masih perlu latihan lebih lanjut lagi. Kemiripan sudah menyerupai buah aslinya. Terakhir keseimbangan buah dan box buah sangat baik.

Berdasarkan data-data yang telah dideskripsikan, dianalisiskan maka diperoleh bahwa karya gambar bentuk buah teknik krayon pada karya 29 dalam penerapan ketepatan komposisi, proporsi, kemiripian bentuk dan gradasi Baik dengan jumlah nilai 85,75.

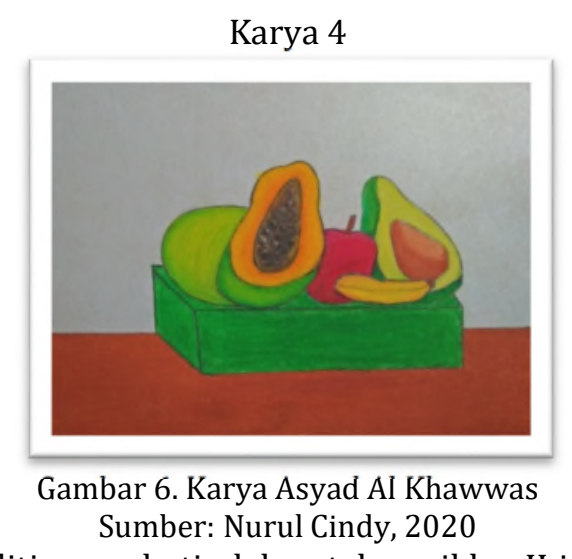

Berdasarkan hasil penelitian, pada tindakan tahap siklus II ini bisa dilihat dari perubahan objek buah dan perubahan pada hasil karya yang lebih meningkat. Salah satu karyanya, Bisa dinilai dari elemen dasar gambar bentuk yaitu komposisi yang sudah baik pada peletakan bidang tengah kertas gambar. Disambung dengan proporsi buah yang sudah tepat dan baik (layak dilihat). Perpaduan warna yang menjadikan gradasi sangat baik. Kemiripan sudah menyerupai buah aslinya. Terakhir keseimbangan buah dan box buah sangat baik.

Berdasarkan data-data yang telah dideskripsikan, dianalisiskan maka diperoleh bahwa karya gambar bentuk buah teknik krayon pada karya 4 dalam penerapan ketepatan komposisi, proporsi, kemiripian bentuk dan gradasi Amat Baik dengan jumlah nilai 90.

Berdasarkan hasil penelitian yang telah dilakukan, hasil belajar gambar bentuk buah dan tingkat pemahaman dasar gambar bentuk pada Pre Test, Siklus I, Siklus II, dapat dipresentasekan pada tabel

Data Hasil Ketuntasan Belajar dari Pre Test, Siklus I dan Siklus II

\begin{tabular}{llllll}
\hline No. & Siklus & Amat Baik & Baik & Cukup Baik & Kurang Baik \\
\hline 1. & Pre Test & o\% & $52 \%$ & $37,8 \%$ & $10,2 \%$ \\
\hline 2. & Siklus I & o $\%$ & $86,7 \%$ & $13,3 \%$ & o $\%$ \\
\hline 3. & Siklus II & $10,34 \%$ & $89,66 \%$ & $0 \%$ & $0 \%$ \\
\hline
\end{tabular}

Data tersebut menunjukkan bahwa terjadinya peningkatan hasil belajar siswa pada setiap tahap-tahapan di kelas dan menandakan kepuasan dan keberhasilan peneliti dalam penelitian tindakan kelas dan kegigihan serta ketekunan dan semangat para siswa dalam bimbingan peneliti selama belajar mengajar di kelas VI-A SD Negeri No. 081232 Sibolga pada semester 2 dengan penerapan metode latihan dan dibantu dengan tambah media mencontoh dari peneliti di papan tulis serta ketekunan siswa dalam memahami dasar gambar bentuk buah.

\section{SIMPULAN}

Berdasarkan hasil analisa data, Pengetahuan yang mulanya minim menjadi mengetahui/memahami suatu materi pokok dasar gambar bentuk buah ini menunjukkan bahwa kemampuan siswa dari tidak baik, naik menjadi karya yang lebih baik dan layak. Pengamatan hasil

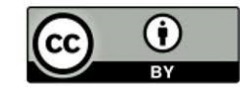


Vol 3, No. 1, Agustus 2020: 171 -177, DOI: https://doi.org/10.34007/iehss.v3i1.245

tindakan setiap siklus telah berhasil dan terjadi peningkatan yang mana masuk pada ketegori penilaian baik dan mencapai ketuntasan. Ini membuktikan keberhasilan tahap demi tahapan pada setiap siklus yang dilakukan oleh peneliti.

\section{DAFTAR PUSTAKA}

Apriyanto, V. (2013). Cepat Dan Mudah Belajar Menggambar Dengan Pensil. Jakarta Selatan: PT. Kawan Kita. Dewi, R. (2015). Profesionalisasi Guru Melalui Penilaian Tindakan Kelas. Medan: UNIMED PRESS.

Ditha. (2012). Pengertian Menggambar Bentuk. Dapat diakses melalui http://dithadithu.blogspot.com/2012/07/Pengertianmenggambar.html. Diakses pada 12-10-2019 pukul 12.57 WIB

Hill, A. (1996). Bagaimana Menggambar. Bandung: Angkasa.

Kartono, G., Mesra, M., \& Azis, A.C.K. (2020). Pengembangan Media Ajar Grafis Komputer Materi WPAP dalam Bentuk E-Book dan Vidio Tutorialbagi Mahasiswa Seni Rupa, Gorga: Jurnal Seni Rupa. 9 (1), 127-132 Lowenfeld, V. (1985). Creative and Mental Growth. Amerika: The Macmilan Company Majid, A. (2014). Strategi Pembelajaran. Bandung: PT Remaja Rosdakarya. Matondang, Z. (2008). Evaluasi Pembelajaran. Medan: UNIMED PRESS. Mesra. (2014). Menggambar Bentuk 1. Medan: UNIMED PRESS. Mulyani, N. (2017). Pengembangan Seni Anak Usia Dini. Bandung: PT Remaja Rosdakarya. Purwanto. (2016). Evaluasi Hasil Belajar. Yogyakarta: PUSTAKA BELAJAR.

Rofian, (2016). Penerapan Metode Pembelajaran Demostrasi Pada Pendidikan Seni Rupa Di Sekolah Dasar. Majalah Ilmiah Pendidikan Dasar. Volume 6 Nomor 2 Desember 2016. Email: rofian@upgris.ac.id Simblet, Sarah. (2005). The Drawing Book. London: Dorling Kindersley Limited 80 Srand. Sinar. (2018). Metode Active Learning. Yogyakarta: CV BUDI UTAMA.

Slameto. (2013). Belajar dan Faktor-Faktor yang mempengaruhinya. Jakarta: PT RINEKA CIPTA. Sugito, dkk. (2015). Evaluasi Hasil Belajar Seni Rupa. Medan: UNIMED PRESS.

Syah, M. (2017). Psikologi Belajar. Depok: PT RAJAGRAFINDO PERSADA.

Tabrani, P. (2012). Bahasa Rupa. Bandung: Kelir.

Yusuf, A.M. (2016). Metode Penelitian Kualitatif, Kuantitatif \& Penelitian Gabungan. Jakarta: Prenadamedia Group. 